\title{
The Cerebrohepatorenal (Zellweger) Syndrome: An Improved Method for the Biochemical Diagnosis and its Potential Value for Prenatal Detection ${ }^{1}$
}

\author{
ADELBERT ROSCHER, BRUNHILDE MOLZER, HANS BERNHEIMER, SYLVIA STÖCKLER, \\ INGOMAR MUTZ, AND FRITZ PALTAUF \\ Department of Paediatrics [A.R., S.S.] University of Graz, Graz; Neurological Institute [B.M., H.B.], University \\ of Vienna, Vienna; Childrens Hospital Leoben [I.M.]; and Department of Biochemistry [F.P.], Technical \\ University of Graz, Graz, Austria
}

\begin{abstract}
The sequence of reactions involved in plasmalogen biosynthesis has been evaluated in cultured fibroblasts of patients with the cerebrohepatorenal syndrome. A double-label, double-substrate incubation using $\left[1-{ }^{14} \mathrm{C}\right]$ hexadecanol and $1-0-\left[9^{\prime}, 10^{\prime}-{ }^{3} \mathrm{H}\right]$ hexadecylglycerol was performed to monitor the relative rates of peroxisomal and microsomal biosynthesic steps. $\left[{ }^{14} \mathrm{C}\right]$ radioactivity associated with 1'-alkenyl groups of plasmalogens was found to be drastically reduced in fibroblasts of affected patients whereas $\left[{ }^{3} \mathrm{H}\right]$ incorporation was apparently normal. This finding is specific for cerebrohepatorenal syndrome fibroblasts since cell lines of patients with childhood adrenoleukodystrophy and neuronal ceroidlipofuscinosis utilized the lipid precursors of plasmalogen biosynthesis at normal rates. The results show that the defect in plasmalogen synthesis in the cerebro-hepato-renal syndrome is restricted to the peroxisomal steps. The finding of normal microsomal biosynthetic steps was exploited to devise a novel diagnostic assay in fibroblasts and amniocytes based on the comparison of $\left[{ }^{3} \mathrm{H} /{ }^{14} \mathrm{C}\right]$ isotope ratios within aldehydes released from plasmalogens by acid hydrolysis. The procedure can be completed with a minimal amount of cells since it renders quantitative analyses unnecessary. Therefore, this technique appears ideally suited for the sensitive and safe prenatal diagnosis of the cerebro-hepato-renal syndrome. (Pediatr Res 19: 930-933, 1984)
\end{abstract}

\section{Abbreviations}

ALD, adrenoleukodystrophy

CHRS, cerebro-hepato-renal syndrome

DHAP, dihydroxyacetonephosphate

NCL, neuronal ceroidlipofuscinosis

VLCFA, very-long-chain fatty acids

The CHRS (Zellweger) is a rare autosomal recessive disorder, clinically characterized by abnormalities in liver and kidney

\section{Received December 13, 1984; accepted May 3, 1985}

Requests for reprints should be addressed to Dr. Adelbert Roscher, Department of Paediatrics. University of Graz. Landeskrankenhaus Graz, Auenbruggerplatz, A8036 Graz, Austria.

Supported by the Fonds zur Förderung der Wissenschaftlichen Forschung in Osterreich (Projekt S5414 and S25/o4).

${ }^{1}$ Presented in part at the Third International Symposium on Inborn Errors of Metabolism in Humans, Munich, March 7-9, 1984. function, severe hypotonia, psychomotor retardation, and dysmorphic features $(1,2)$.

This syndrome is accompanied by a variety of biochemical disturbances such as hyperpipecolic acidemia, hepatic and cerebral glycogen storage (2), elevated $\operatorname{VLCFA}(3,4)$, abnormal bile acids $(5,6)$, dicarboxylic aciduria, and diminished levels of plasmalogens $(7,8)$. Most of the abnormalities may relate to the absence of peroxisomes and/or to severely impaired mitochondrial functions in patients $(9,10)$.

Since the infants usually die within the 1 st yr of life, an early and precise biochemical diagnosis is important for providing adequate genetic counseling. The study of VLCFA, particularly of hexacosanoic acid $\left(C_{26: 0}\right)$ and hexacosenoic acid $\left(C_{26: 1}\right)$ in amniotic fluid and in cultured amniocytes has been proposed for prenatal diagnosis $(3,11)$. Alternately, diagnosis based on measurement of DHAP-acyltransferase-the first enzyme in the pathway leading to plasmalogen biosynthesis (12) - has been suggested (13). However, the complete biosynthetic pathway leading to plasmalogens has not been investigated so far in CHRS. In this study we used $\left[1-{ }^{14} \mathrm{C}\right]$ hexadecanol and $\left[9^{\prime}, 10^{\prime}-{ }^{3} \mathrm{H}\right]$ hexadecylglycerol to investigate both the peroxisomal and microsomal steps of plasmalogen biosynthesis. The finding of normal microsomal steps of plasmalogen formation was exploited to devise a novel technique for the biochemical diagosis of CHRS.

\section{MATERIALS AND METHODS}

$\left[1-{ }^{14} \mathrm{C}\right]$ hexadecanol was purchased from Amersham (England) and diluted with hexadecanol to a specific activity of $11.4 \mathrm{mCi}$ / mmol. $\left[9^{\prime}, 10^{\prime}-{ }^{3} \mathrm{H}\right]-s n$-hexadecylglycerol (specific radioactivity $5.5 \mathrm{mCi} / \mathrm{mmol}$ ) was prepared by chemical synthesis (14) (on request it is available from the authors). Unlabeled phospholipid standards were prepared in our laboratory by conventional chromatographic procedures.

Culture medium, enzyme solutions, and additions for the culture media were from Serva (Heidelberg, FRG), bovine serum albumin from Armour Pharmaceutical Co. (Phoenix, AZ). All other reagents were of analytical grade and obtained from commercial sources.

Cell culture. Three of the cell strains were obtained from the Human Genetic Mutant Cell Repository (Camden, NJ): CHRS1 (GM 0228), CHRS 2 (GM 4340), and ALD 3 (GM 4933). ALD 1 and ALD 2 were kindly donated by M. Vetterlein, Institute for Tumor Biology and Cancer Research, University of Vienna. Fibroblast samples of CHRS-heterozygotes were friendly provided by $\mathrm{H}$. Moser, John F. Kennedy Institute, Baltimore, MD. 
All other cell strains were initiated at the Paediatric Tissue Culture Unit, University of Graz, Medical School.

Control skin biopsies were taken on the occasion of minor surgery (herniotomia) from otherwise healthy children. Diagnosis of ALD was based on neurological findings and was confirmed by increased $\mathrm{C}_{26: 0}$ fatty acid levels in leukocytes and fibroblasts (15). Patients with NCL were diagnosed by the typical clinical and ultrastructural findings (16) and the patient with CHRS was recognized by the typical clinical characteristics (2) and by the presence of hyperpipecolic acidemia.

Stock cultures of human fibroblasts were grown in Eagle's basal medium supplemented with Earle's salts, $10 \%$ fetal calf serum, and $2 \mathrm{mM}$ glutamine as previously described (17). Subcultures, initiated with $1 \times 10^{6}$ cells in $60-\mathrm{mm}$ dishes (Falcon Plastics, CA), were grown to confluency and the standard medium was renewed the day before experiments were carried out.

Incubations. Incubations were carried out with fibroblast cultures that had been equilibrated for $30 \mathrm{~min}$ at $37^{\circ} \mathrm{C}$ in incubation medium consisting of serum-free Dulbecco's minimal essential medium containing $0.05 \%$ bovine albumin. Stock solutions of radiolabeled substrates were prepared in absolute ethanol and diluted with the incubation medium to give the desired amount of $\left[{ }^{3} \mathrm{H}_{-}{ }^{14} \mathrm{C}\right]$ lipid mixture. The final ethanol concentration did not exceed $0.1 \%$. This solution was sonicated for $20 \mathrm{~s}$, and a 2$\mathrm{ml}$ aliquot containing $0.3 \mu \mathrm{Ci}(26 \mathrm{nmol})$ of $\left[1-{ }^{14} \mathrm{C}\right]$ hexadecanol and $3 \mu \mathrm{Ci}(600 \mathrm{nmol})$ of $\left[9^{\prime}, 10^{\prime}-^{3} \mathrm{H}\right]$ hexadecyl-sn-glycerol was added to the fibroblast monolayers. At the times indicated cells were washed twice with phosphate-buffered saline at $4^{\circ} \mathrm{C}$, scraped off with a rubber policeman, and collected by centrifugation.

Analyses. Fibroblast pellets were disintegrated by sonication in $1 \mathrm{ml}$ of water and total cellular lipids were then extracted according to Folch et al. (18). The plasmalogen content of the phosphatidylethanolamine and phosphatidylcholine fractions was determined by two-dimensional thin-layer chromatography (19). Silica gel PF 60 plates were first developed in chloroformmethanol-water $(65: 25: 4$, by vol), dried, exposed to fumes of concentrated $\mathrm{HCl}$, and finally developed in the second dimension with the same solvent. Phospholipid phosphorus was quantitated according to the procedure of Rouser et al. (20). When radioactively labeled substrates were supplemented to the cultures, the separation of labeled aldehydes released from plasmalogens by acid catalyzed hydrolysis was accomplished by thin-layer chromatography using a dual-development technique according to Paltauf (21). Aliquots of the lipid extracts were applied to thinlayer plates coated with $0.5 \mathrm{~mm}$ silica gel H (Merck, Darmstadt, FRG). To each spot $0.2 \mathrm{mg}$ of ox brain phosphatidylethanolamine and $0.2 \mathrm{mg}$ hexadecylglycerol were added to carriers. The plate was first developed with diethylether $/ \mathrm{H}_{2} \mathrm{O}(100 / 0.25$, by $\mathrm{vol}$ ) to remove radioactively labeled neutral lipids, then exposed to $\mathrm{HCl}$ fumes for $10 \mathrm{~min}$, and developed twice with light petroleum/diethylether $(95 / 5$, by vol) to a distance of $10 \mathrm{~cm}$ from the origin. Spots corresponding to aldehydes were visualized by brief exposure to iodine vapor, signed, and decolorized under a stream of air. Radioactivity was measured after the spots were transferred directly into counting vials, using a xylene-based scintillation cocktail.

Isolation of fatty acids, esterification, and analysis of fatty acid methylesters was performed as reported previously (15).

\section{RESULTS AND DISCUSSION}

Recent findings demonstrate that CHRS fibroblasts exhibit abnormally elevated levels of VLCFA similar to those found in $\operatorname{ALD}(4,15,22)$. In this study (Table 1) concentrations of hexacosanoic acid $\left(\mathrm{C}_{26: 0}\right)$ were consistently higher in CHRS fibroblasts $(0.38 \pm 0.17 \mu \mathrm{g} / \mathrm{mg}$ lipids $)$ and ALD fibroblasts $(0.46$ $\pm 0.18 \mu \mathrm{g} / \mathrm{mg}$ lipid) as compared to control cell strains $(0.14 \pm$ $0.04 \mu \mathrm{g} / \mathrm{mg}$ lipid). $\mathrm{C}_{26: 0} / \mathrm{C}_{22: 0}$ ratio was elevated in CHRS and
Table 1. VLCFA in cultured fibroblasts*

\begin{tabular}{lcc}
\hline & $\begin{array}{c}\mathrm{C}_{26: 0} \\
(\mu \mathrm{g} / \mathrm{mg} \text { lipid })\end{array}$ & $\begin{array}{c}\mathrm{C}_{26: 0} \\
\mathrm{C}_{22: 0}\end{array}$ \\
\hline $\mathrm{Co}_{1} \dagger$ & 0.17 & 0.23 \\
$\mathrm{Co}_{2}$ & 0.11 & 0.34 \\
& & \\
$\mathrm{NCL}$ & 0.10 & 0.22 \\
$\mathrm{NCL}_{2}$ & 0.10 & 0.43 \\
& & \\
$\mathrm{ALD}_{1}$ & 0.53 & 0.64 \\
$\mathrm{ALD}_{2}$ & 0.60 & 0.76 \\
$\mathrm{ALD}_{3}$ & 0.26 & 0.91 \\
$\mathrm{CHRS}_{1}$ & & \\
$\mathrm{CHRS}_{2}$ & 0.31 & 1.60 \\
$\mathrm{CHRS}_{3}$ & 0.26 & 1.67 \\
\hline
\end{tabular}

* Fatty acids of total lipids extracted from fibroblasts were analyzed by gas-liquid chromatography as their methyl esters (15).

+ Control.

Table 2. Plasmalogen content of cultured human fibroblasts*

\begin{tabular}{lcc}
\hline & $\begin{array}{c}\text { Diacyl-GPE } \dagger \\
\text { (Phosphatidyl-ethanolamine) }\end{array}$ & $\begin{array}{c}\text { 1-Alkenylacyl-GPE } \\
\text { (Plasmalogen) }\end{array}$ \\
\cline { 2 - 3 } & \multicolumn{1}{c}{ \% of total phospholipids) } \\
\hline $\mathrm{Co}_{1} \ddagger$ & 12.32 & 12.83 \\
$\mathrm{CO}_{2}$ & 11.77 & 14.68 \\
& & \\
$\mathrm{NCL}_{1}$ & 12.28 & 10.28 \\
$\mathrm{NCL}_{2}$ & 11.76 & 11.68 \\
& & \\
$\mathrm{ALD}$ & 13.22 & 9.78 \\
$\mathrm{ALD}$ & 13.72 & 10.93 \\
$\mathrm{ALD}_{3}$ & 13.76 & 12.10 \\
& & \\
$\mathrm{CHRS}_{1}$ & 23.20 & 5.3 \\
$\mathrm{CHRS}_{2}$ & 18.68 & 2.5 \\
$\mathrm{CHRS}_{3}$ & 17.82 & 3.3 \\
\hline
\end{tabular}

* Total lipids extracted from fibroblasts were analyzed by two-dimensional reaction thin-layer chromatography as described in "Materials and Methods." Only the data obtained for the ethanolamine glycerophospholipid fraction are shown in Table 2 since the plasmalogen content of other phospholipid classes was negligibly low.

$\dagger$ Glycerophosphoethanolamine.

$\ddagger$ Control.

ALD fibroblasts as well. The higher $\mathrm{C}_{26.0} / \mathrm{C}_{22.0}$ ratio in CHRS than in ALD cells was due to the relatively low $C_{22: 0}$ levels in CHRS fibroblasts (data not shown). The VLCFA levels and $\mathrm{C}_{26: 0} /$ $\mathrm{C}_{22: 0}$ ratios in fibroblasts of patients with NCL were within the normal range.

It has been proposed that ALD and CHRS share some impaired peroxisomal functions although the exact mechanisms underlying the VLCFA accumulations in these two diseases appear to be different (3).

Plasmalogen deficiency in tissues of CHRS is also suspected to be due to peroxisomal abnormalities $(7,8)$. Recent experiments have shown (13) that acyl coenzyme A:dihydroxyacetonephosphate acyltransferase is virtually absent from CHRS cells (brain, liver, and fibroblasts). So far, however, the specificity of this finding has not been systematically evaluated. For example, a virtual absence of plasmalogens in brain extracts from patients with NCL has been reported (16). Therefore we determined total plasmalogen levels in cultured fibroblasts of patients with CHRS, ALD, and NCL (Table 2). Phospholipid analyses of fibroblast lipid extracts revealed a pronounced reduction of total 

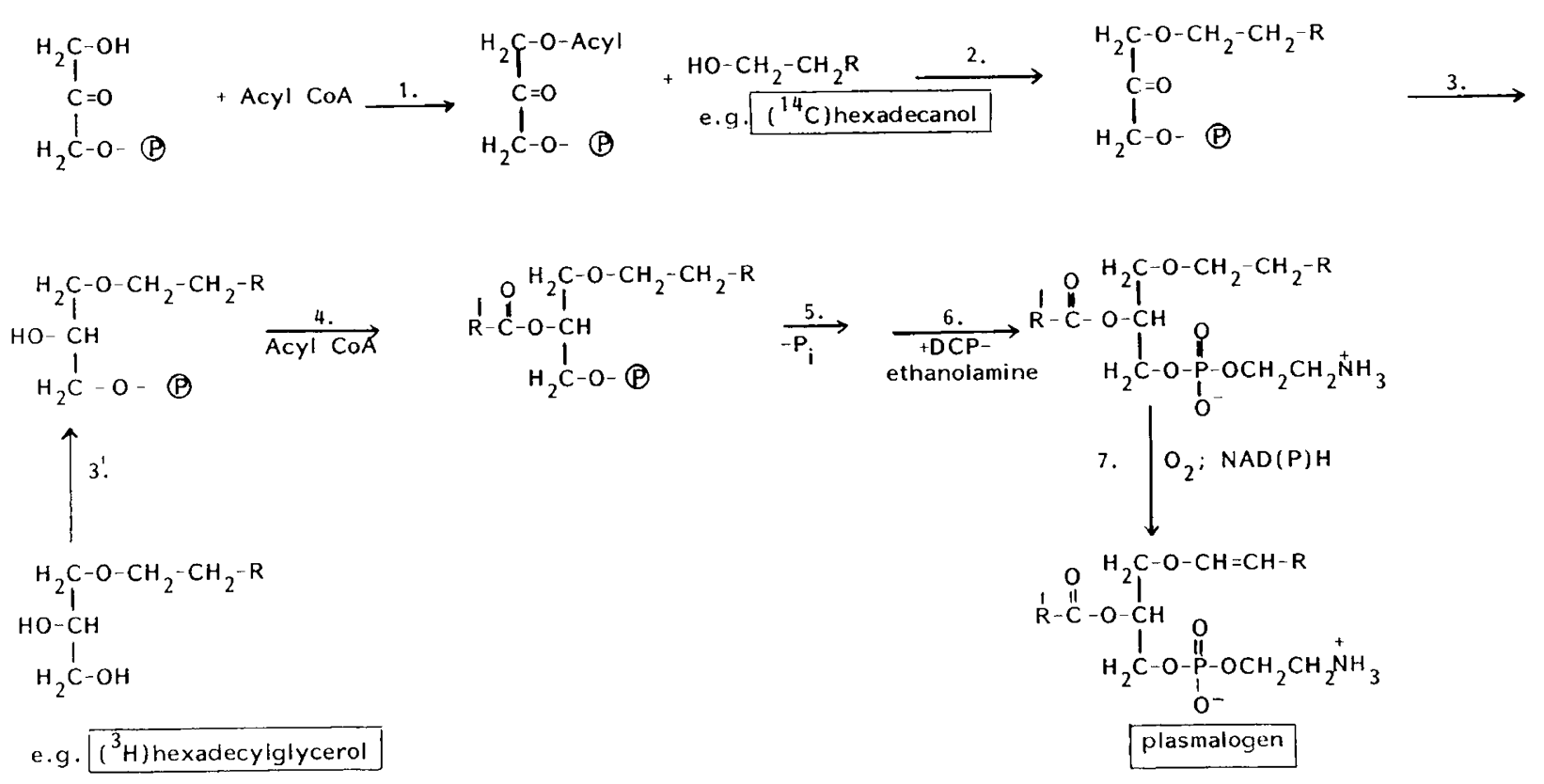

Fig. 1. Sequence of reactions involved in plasmalogen biosynthesis in aerobic cells.

plasmalogen content in CHRS fibroblasts $(4.0 \pm 1.1 \%$ of total lipids versus $13.7 \pm 1.3 \%$ in controls) that is balanced by somewhat increased amounts of phosphatidylethanolamine (19.9 \pm $2.9 \%$ in CHRS versus $12.1 \pm 0.4 \%$ in controls). No differences in the distribution of the other phospholipids were found (data not shown). The fibroblast phospholipid pattern of patients with ALD and NCL was indistinguishable from normal controls.

The sequence of reactions involved in plasmalogen biosynthesis in aerobic cells is depicted in Figure 1. Formation of acyl DHAP (reaction 1) that is utilized for ether lipid synthesis, and alkyl DHAP synthase (reaction 2) are restricted to peroxisomes (12). The subsequent reactions leading to the formation of 1-0alkyl-2-acyl glycerophosphoethanolamine are catalyzed by enzymes that are also involved in diacyl glycerophosphoethanolamine synthesis and are localized in the endoplasmic reticulum. Whereas reaction 1 was found to be deficient in CHRS cells (13), so far no data are available concerning the activity of the key enzymes $(23,24)$ of plasmalogen biosynthesis (reactions 2 and 7) in CHRS cells.

The method for the biochemical diagnosis of CHRS described here was devised assuming that the utilization of long-chain alcohols $\left(e . g .\left[{ }^{14} \mathrm{C}\right]\right.$ hexadecanol $)$ for plasmalogen synthesis should be impaired in the absence of peroxisomes. On the other hand, the microsomal conversion of alkylglycerols $\left(\right.$ e.g. $\left[{ }^{3} \mathrm{H}\right]$ hexadecylglycerol) to plasmalogens which proceeds via reactions $3^{\prime}$ to 7 should be normal. Consequently, a double-label, double-substrate incubation using $\left[1-{ }^{14} \mathrm{C}\right]$ hexadecanol and $1-0-\left[9^{\prime}, 10^{\prime}-{ }^{3} \mathrm{H}\right]$ hexadecylglycerol was performed to monitor relative rates of peroxisomal and microsomal steps of plasmalogen biosynthesis in fibroblasts. As shown in Table 3, incorporation of $\left[{ }^{3} \mathrm{H}\right]$ hexadecylglycerol into the $1^{\prime}$-alkenyl groups of plasmalogens proceeded at approximately equal rates in CHRS cells and controls. In contrast, utilization of $\left[1-{ }^{14} \mathrm{C}\right]$ hexadecanol for plasmalogen synthesis was drastically reduced in CHRS cells $(0.6 \pm 0.3 \%$ in CHRS versus $15.0 \pm 2.9 \%$ in controls).

By calculating the $\left[{ }^{3} \mathrm{H} /{ }^{14} \mathrm{C}\right]$ isotope ratio within alkenyl groups of plasmalogens a 15-to 60 -fold difference between CHRS and controls was found. This difference was largely independent of the incubation time, although the absolute $\left[{ }^{3} \mathrm{H} /{ }^{14} \mathrm{C}\right]$ ratios increased with time (e.g. 0.2-0.9 in controls and 3-15 in CHRS from $6-24 \mathrm{~h}$ of incubation). For practical purposes an overnight incubation (16-20 h) was routinely employed.

These results demonstrate that the defect in plasmalogen synthesis in CHRS cells is restricted to peroxisomal steps (reactions
Table 3. Relative contribution of lipid precursors to plasmalogen synthesis in cultured human fibroblasts*

\begin{tabular}{|c|c|c|c|}
\hline & \multicolumn{2}{|c|}{$\begin{array}{c}\text { Radioactivity } \\
\text { in } 1^{\prime}- \\
\text { alkenylgroups } \\
\text { (\% of total } \\
\text { incorporated) }\end{array}$} & \multirow[b]{2}{*}[{}^{3}\mathrm{H}/{}^{14}\mathrm{C}]{ Ratio } \\
\hline & {$\left[{ }^{3} \mathrm{H}\right]$} & {$\left[{ }^{14} \mathrm{C}\right]$} & \\
\hline $\mathrm{Co}_{1} \dagger$ & 10.9 & 17.9 & 0.61 \\
\hline $\mathrm{CO}_{2}$ & 11.2 & 12.2 & 0.91 \\
\hline $\mathrm{CO}_{3}$ & 10.4 & 15.0 & 0.69 \\
\hline $\mathrm{NCL}_{1}$ & 10.2 & 17.0 & 0.60 \\
\hline $\mathrm{NCL}_{2}$ & 11.9 & 13.1 & 0.91 \\
\hline $\mathrm{ALD}_{1}$ & 9.4 & 18.6 & 0.51 \\
\hline $\mathrm{ALD}_{2}$ & 4.3 & 4.6 & 0.93 \\
\hline $\mathrm{ALD}_{3}$ & 8.7 & 9.9 & 0.88 \\
\hline $\mathrm{CHRS}_{1}$ & 13.4 & 0.86 & 15.6 \\
\hline $\mathrm{CHRS}_{2}$ & 12.3 & 0.31 & 39.6 \\
\hline $\mathrm{CHRS}_{3}$ & 12.7 & 0.61 & 20.8 \\
\hline CHRS-HE $1 \frac{7}{7}$ & 8.2 & 9.9 & 0.83 \\
\hline CHRS-HE ${ }_{2}$ & 8.3 & 10.0 & 0.83 \\
\hline CHRS-HE 3 & 9.2 & 14.5 & 0.63 \\
\hline
\end{tabular}

* Radioactivity associated with aldehydes released after acid treatment of total phospholipids was measured and related to the total radioactivity incorporated into fibroblast lipids. Incubations were for $16 \mathrm{~h}$. Total radioactivity in lipid extracts $\left(\left[{ }^{3} \mathrm{H}\right]\right.$ from $\left[9^{\prime}, 10^{\prime}-{ }^{3} \mathrm{H}_{2}\right]$ hexadecyl-snglycerol; $\left[{ }^{14} \mathrm{C}\right]$ from $\left[1-{ }^{14} \mathrm{C}\right]$ hexadecanol) was essentially identical with all types of cells.

$\dagger$ Control.

$\ddagger$ Heterocygotes.

1 and 2 in the scheme), whereas the microsomal reactions obviously proceed at normal rates. Therefore, one could speculate that at least the symptom of plasmalogen deficiency in CHRS might be accessible to supplementation therapy, e.g. by the administration of alkylglycerolipids.

Cell lines of patients with childhood ALD and NCL were used as pathological controls because of reported peroxisomal dysfunction (4) or proposed plasmalogen deficiency in brain (16). 
Cell strains of both diseases showed normal utilization of the two precursors of plasmalogen biosynthesis. This is consistent with the hypothesis that impaired ether lipid biosynthesis is specific for CHRS.

We further show by this technique that ether lipid biosynthesis in fibroblasts of obligate heterozygotes is in the range of controls. This is in agreement with the demonstration of normal acyl CoA DHAP acyltransferase activity in CHRS heterozygote fibroblasts (13). The failure to demonstrate a simple gene dosage relationship suggests that the basic defect in CHRS resides rather in the assembly of functional peroxisomes than in a specific enzyme involved in ether lipid synthesis.

A specific and reliable biochemical method for the diagnosis of CHRS is essential to differentiate this disease from other causes of the "floppy infant syndrome." For practical purposes, the double-label, double-substrate technique reported herein offers several advantages. Since microsomal plasmalogens synthesis from alkyl glycerol precursors is normal in CHRS, $\left[{ }^{3} \mathrm{H}\right]$ hexadecylglycerol can be utilized to serve as an internal reference. Diagnosis of CHRS can be established simply by comparing the $\left[{ }^{3} \mathrm{H} /{ }^{14} \mathrm{C}\right]$ isotope ratio within aldehydes released from plasmalogens by acid hydrolysis (Table 3 ). This renders quantitative analyses (e.g. of lipids, enzyme activities, or cell protein) unnecessary and allows diagnosis from a limited amount of cells. $\left[{ }^{3} \mathrm{H} /\right.$ $\left.{ }^{14} \mathrm{C}\right]$ isotope ratios similar to those shown in Table $3(0.5-1.0$ for controls, 15-50 for CHRS) were obtained with grossly different amounts (10-200 $\mu \mathrm{g}$ of protein) of normal and CHRS fibroblasts. Values obtained for normal amniocytes $(10 \mu \mathrm{g}$ of protein) did not differ from those of control fibroblasts (data not shown).

The calculation of the $\left[{ }^{3} \mathrm{H} /{ }^{14} \mathrm{C}\right]$ isotope ratio appears to provide a high degree of sensitivity due to the great difference between disease and control (15-to 60 -fold). While the existing techniques for the diagnosis of a CHRS child or fetus appear to work well the method described herein may be a useful supplement especially under conditions when high diagnostic sensitivity and safety is mandatory.

Note added in proof. Since submission of this manuscript, Schutgens et al. (25) have reported prenatal diagnosis of two fetuses with Zellweger syndrome by measurement of DHAPacyltransferase and incorporation of $\left[1-{ }^{14} \mathrm{C}\right]$ hexadecanol into plasmalogens of amniotic fluid cells.

Datta et al. (26) have measured the activity of various enzymes catalyzing the biosynthesis of glycerol-ether lipids in tissues of Zellweger syndrome patients, corroborating the findings reported here by enzymatic techniques.

Acknowledgments. The authors thank Mrs. E. Zenzmayer, H. Stütz, and Ms. M. Korschinsky for skillful technical assistance.

\section{REFERENCES}

1. Bowen P. Lee CSN, Zellweger H, Lindenberg R 1964 A familial syndrome of multiple congenital defects. Bull Johns Hopkins Hosp 114:402-414

2. Kelley RI 1983 Review: the cercbrohepatorenal syndrome of Zellweger, morphologic and metabolic aspects. Am J Med Genet 16:503-517

3. Moser AE. Singh I, Brown FR, Solish GI, Kelley RI, Benke PJ, Moser HW
1984 The cerebrohepatorenal (Zellweger) syndrome. Increased levels and impaired degradation of very-long-chain fatty acids and their use in prenatal diagnosis. N Engl J Med 310:1141-1146

4. Brown FR, McAdams AJ, Cummins JW, Konkol R, Singh I, Moser AB, Moser HW 1982 Cerebro-hepato-renal (Zellweger) syndrome and neonatal adrenoleukodystrophy: similarities in phenotype and accumulation of very long chain fatty acids. Johns Hopkins Med J 151:344-350

5. Hanson RF. Williams GC, Grabowski G, Sharp HL 1979 Defects of bile acid synthesis in Zellweger's syndrome. Science 203:1107-1108

6. Gustafsson J, Gustavson KH, Karlaganis G, Sjövall J 1983 Zellweger's cerebrohepato-renal syndrome-variations in expressivity and in defects of bile acid synthesis. Clin Genet 24:313-319

7. Heymans HSA, Schutgens RBH, Tan R, van den Bosch H, Borst P 1983 Severe plasmalogen deficiency in tissues of infants without peroxisomes (Zellweger syndrome). Nature (Lond) 306:79-70

8. Heymans HSA, van den Bosch $\mathrm{H}$, Schutgens RBH, Tegelaers WHH, Walther JU, Müller-Höcker J, Borst P 1984 Deficiency of plasmalogens in the cerebro-hepato-renal (Zellweger) syndrome. Eur J Pediatr 142:10-15

9. Goldfischer S, Moore CL, Johnson AB, Spiro AJ, Valsamis MP, Wisniewsky HK, Ritch RH, Norton WT, Rapin I, Gartner LM 1973 Peroxisomal and mitochondrial defects in the cerebro-hepato-renal syndrome. Science 182:62-64

10. Trijbels JMF, Berden JA, Monnens LAH, Willems JL, Janssen AJM, Schutgens RBH, van den Broek-van Essen M 1983 Biochemical studies in the liver and muscle of patients with Zellweger syndrome. Pediatr Res 17:514-517

11. Björkhem I, Sisfontes A, Boström B, Kase F, Hagenfeldt L. Blomstrand R 1984 Possibility of prenatal diagnosis of Zellweger syndrome. Lancet 1:1234-1235

12. Hajra AK, Burke CL, Jones CL 1979 Subcellular localization of acylcoenzyme A: dihydroxyacetone phosphate acyltransferase in rat liver peroxisomes. Biol Chem 254:10896-10900

13. Schutgens RBH, Romeyn GJ, Wanders RJA, van den Bosch H, Schrakamp $G$, Heymans HSA 1984 Deficiency of acyl-CoA: dihydroxyacetone phosphate acyltransferase in patients with Zellweger (cerebro-hepato-renal) syndrome. Biochem Biophys Res Commun 120:179-184

14. Hermetter A. Paltauf $F 1983$ Procedures for the synthesis of ether lipids. In: Mangold HK. Paltauf $F$ (eds) Ether Lipids: Biochemical and Biomedical Aspects. Academic Press, New York, pp 389-420

15. Molzer B, Bernheimer H, Heller R, Toifl K, Vetterlein M 1982 Detection of adrenoleukodystrophy by increased $\mathrm{C}_{26: 0}$ fatty acid levels in leukocytes. Clin Chim Acta 125:299-305

16. Zeman W, Dyken P 1969 Neuronal ceroidlipofuscinosis (Batten's disease): relationship to amaurotic familial idiocy. Pediatrics 44:570-583

17. Roscher AA, Schmid AJ, Hadorn B, Wiesmann UN 1980 Enhanced adenosine $3^{\prime}: 5^{\prime}$-monophosphate response to betaadrenergic stimulation in cystic fibrosis fibroblasts after removal of coditioned medium. Pediatr Res 14:261-265

18. Folch J, Lees M, Stanley GHS 1957 A simple method for the isolation and purification of total lipids from animal tissues. J Biol Chem 226:497-511

19. Horrocks LA 1968 The alk-1-enylgroup content of mammalian myelin phosphoglycerides by quantitative two-dimensional thin-layer chromatography. J Lipid Res 9:469-472

20. Rouser G, Fleischer S, Yamamoto A 1970 Two dimensional thin-layer chromatographic separation of polar lipids and determination of phospholipid by phosphorus analysis of spots. Lipids 5:494-496

21. Paltauf F 1978 Isolation of soluble proteins capable of stimulating aerobic plasmalogen biosynthesis. Eur J Biochem 85:263-270

22. Singh I, Moser AE, Moser HW, Kishimoto Y 1984 Adrenoleukodystrophie: Impaired oxidation of very long chain fatty acids in white blood cells, cultured skin fibroblasts, and amniocytes. Pediatr Res 18:286-290

23. Hajra A 1984 Biosynthesis of O-alkylglycerol ether lipids. In: Mangold HK Paltauf F (eds) Ether Lipids: Biochemical and Biomedical Aspects. Academic Press, New York, pp 85-106

24. Paltauf F 1983 Biosynthesis of 1-0-(1'Alkenyl) glycerolipids (Plasmalogens) In: Mangold HK, Paltauf F (eds): Ether Lipids: Biochemical and Biomedical Aspects. Academic Press, New York, pp 107-128

25. Schutgens RBH, Heymans HSA. Wanders RJA, vd Bosch H, Schrakamp C 1984 Prenatal detection of Zellweger syndrome. Lancet 2:1339-1340

26. Datta NS, Wilson GN, Hajra AK 1984 Deficiency of enzymes catalyzing the biosynthesis of glycerol-ether lipids in Zellweger syndrome. A new category of metabolic disease involving the absence of peroxisomes. N Engl $J$ Med $311 / 17: 1080-1083$ 